\title{
Editorial
}

\section{Introduction to "Psychology, Global Threats, Social Challenge, and the COVID-19 Pandemic: European Perspectives"}

\author{
Nicola Gale ${ }^{1}$ and Bernd Roehrle ${ }^{2}$ \\ ${ }^{1}$ European Federation of Psychologists' Associations, Brussels, Belgium \\ 2 Department of Psychology, University of Marburg, Germany
}

\section{COVID-19 in the European Context}

The European Centre for Disease Prevention and Control, an agency of the European Union, has described COVID-19 as an "unprecedented threat" and "highly disruptive to society, both economically and socially" (European Centre for Disease Prevention and Control, 2020). The SARS$\mathrm{CoV}-2$ pandemic is also mentioned as a historical event and challenge by national bodies, for example, by the policy-oriented National Science Council in Germany (e.g., Council of the Sciences, 2021). Indeed, pandemics of this kind, while not new, are rare and so far-reaching in their quantitative and qualitative impact that they can correctly be categorized as historical events (Schenk, 2017), and can come as a shock not only to the public but also to policymakers, administrators, and scientists.

It is undisputed that, based on the epidemiological data presented, this pandemic is not only a serious health threat but is also historically significant for social, economic, and psychological reasons.

COVID-19, its variants, and the intervention measures taken against it produced serious social, economic, and psychological consequences and still do. These consequences were countered with considerable effort. Therefore, the pandemic has been the focus of major political and economic action by the European Commission, with a top-level response team addressing medical, mobility, and economic challenges (European Commission, 2020a). Interestingly, this practical - and financial - focused response, which has committed €2.018 trillion, and which is the largest stimulus package ever financed in Europe to help rebuild a post-COVID-19 Europe, has not by any means excluded the psychological aspects. The European value of solidarity has been much trumpeted, illustrated for example, by the European Solidarity Tracker (European Council on Foreign Relations, 2020), which gathered and disseminated instances of pan-European solidarity throughout the earlier stages of the coronavirus crisis. Such actions were framed by European Commission President Ursula von der Leyen, when she spoke at the European Parliament Plenary on the European coordinated response to the COVID-19 outbreak in Brussels on March 26, 2020, as examples of "love and compassion" and working together "with one big heart" (European Commission, 2020b).

This response also included considerable scientific efforts from a wide range of disciplines. Based on data from PubMed, a biomedical data portal, the keywords "COVID-19 or coronavirus or 2019-ncov or sars-cov-2 or cov-19" cited a total of 280 hits in 2019; as of September 2021, there are now 156,757 publications. The discipline of psychology was also involved. In the psychology-oriented database PsycLit, no hits were found in 2019; from 2020 to September 2021, there are now 3,406 references.

\section{Aims of This Special Issue}

In this context, at the beginning of July 2020, in our Call for Papers as guest editors of the European Psychologist under the heading "Psychology, Global Threats, Social Challenge, and the COVID-19 Pandemic: European Perspectives," we aimed to ask questions across the discipline about the extent to which psychological research has dealt with the COVID19 specific phenomena. We were also interested in the contextual and individual conditions of the psychological processing of the threat and the associated consequences and interventions. In doing so, we hoped for an overview of where psychological research has had successes and where there are still gaps, and how this has developed in a relatively short period of time (Roehrle \& Gale, 2020).

This gave rise to the hope that the productivity of COVID-19 research in psychology would be as highly 
efficient as that of research as a whole. Returning to the example of the German government (Council of the Sciences, 2021), it is claimed there that science during this crisis has proven to be fast and highly adaptable and has established a great closeness to politics and the public. Socially- and behaviorally oriented research traditions pointed to the possibilities that psychological approaches hold in terms of knowledge about human behavior and actions that could be taken in the pandemic. The research related to other disasters also offers theoretical, methodological, and practical possibilities for dealing with COVID-19. Bavel and colleagues (2020) explore a number of access points to help align public behavior with the needs of public health, with references to the results of numerous preceding studies. These access points include approaches to dealing with the perception of and response to threat; aspects of the social context such as social norms, social inequality, culture and polarization; scientific communication; aligning individual and collective interests; leadership including trust; and stress and coping (Bavel et al., 2020). Bavel and colleagues (2020) point out the limits of knowledge and limits of generalizability of that knowledge while at the same time providing insights from the psychological and behavioral evidence base for dealing with COVID-19 and its consequences.

In drawing on the existing evidence base and generalizing it to a pandemic, however, the specificity of special theories and methods are not highlighted in such a way that one can recognize new, phenomenon-specific constructs. References to scientifically necessary innovations can remain vague. This stance could, in some circumstances, be seen as serving the causes of client, profession, or interest group and may not, therefore, point out the limits of previous methods and theories on comparable phenomena. Moreover, analyses such as those by Almeda and colleagues (2021) show that this approach can run the risk of psychologizing many of the problems instead of looking at them either phenomenologically or in the context of different sciences (e.g., structural and individual aspects of unemployment against the background of the global threat).

Position papers on COVID-19 in different subfields of psychology are rare. As position papers, they remain largely affirmative and therefore report the current state of knowledge without pandemic-specific theoretical and methodological approaches (e.g., Gruber et al., 2021; Kniffin et al. 2021; Sigahi et al., 2021). Underlying this business-as-usual or affirmative attitude might be the perception that the consequences of the COVID-19 crisis can be deduced from stressors in crisis-free times (e.g., unemployment, social inequality, social isolation on the one hand, but also solidarity on the other). It may also be regarded as an entirely reasonable way to use the existing evidence base in a new and challenging context that requires urgent amelioration until such times as further evidence emerges. In such circumstances, it is naturally obvious to repeat what is known. Only when the various phenomena in dealing with the pandemic acquire a meaning that Tyhurst (1951), among others, called the disaster syndrome, could the particular nature of this pandemic and severity of its consequences become clear. This raises the question of how the consequences of the pandemic might be exacerbated by the extent of our ability to understand it, predict its course, control it, and the extent of the existential threat it poses. This may then either expand or call into question the respective psychological perspectives, theories, and methods.

This affirmative attitude which may be interpreted as policy-justifying can be contrasted by many critical positions of independent science fields. These critical positions focus not only on the lack of innovative attitudes but also on other research deficits that can also affect psychology. Various authors complain about the following shortcomings of COVID-19 research, partly deriving the criticisms from surveys of scientists themselves (Carley et al., 2020; Holmes et al., 2020; Kasherman et al., 2021; Rijs \& Fenter, 2021; Zeeb et al., 2021):

1. Research has been carried out with predominantly small studies.

2. Longitudinal studies have remained comparatively rare.

3. There are only a few randomized studies (e.g., on preventive measures).

4. Shortcomings in ethical obligations are highlighted (e.g., a lack of informed consent).

5. Clinical studies that have also investigated the effect on other diseases from the point of view of their course are presented too rarely.

6. Various risk groups were neglected (e.g., people with diabetes).

7. The pandemic has had only a minor impact on everyday research; it has become of little importance for topic-related fundraising. It is also feared that the pandemic will hinder the funding of other research topics.

8. There has been a low transfer of scientific findings to political decision-makers.

9. Networked research in interdisciplinary contexts and in the sense of future preparatory cooperative activities is lacking.

10. The criteria of Evidence-Based Medicine (EBM) have not been sufficiently flexible (e.g., to allow for the use of new methodologies).

It remains to be examined whether and in which places the following Special Issue takes these criticisms into account and does not also present only affirmative research results. As guest editors, we have the impression that this 
special issue has succeeded, at least in part, in the following ways:

1. The overview character desired for the European Psychologist is emphasized, and systematic and also meta-analytically validated study results are presented. This reduces the chance of a selective presentation of research results. The use of Preferred Reporting Items for Systematic Reviews and Meta-Analyses (PRISMA) has been encouraged, and all authors have been asked transparently to state their search criteria to enable replication.

2. It has been possible to provide specific fields within psychology with works in this sense. Thus, mental health, social psychology, and community psychology are represented.

3. Specific sub-themes are also examined with a closer look: loneliness, COVID-19 anxiety, aversive personality traits, use of mass media, conspiracy theories, age effects, and migration effects.

4. Large studies are presented, and the view of interrelated research results is also provided.

5. Methodologically innovative, ecologically significant studies, including longitudinal studies, are presented.

6. Theoretical approaches are specified in a not only affirmative sense with regard to the pandemic.

7. Some attention has been paid to particular groups at risk.

8. There is clear transferability of some of the findings to policymakers.

We now invite the reader to consider the papers in terms of the questions we have considered above.

\section{Psychology, Global Threats, Social Challenge, and the COVID-19 Pandemic: European Perspectives}

\section{The Social and Community Level}

Rudert and colleagues (2021) write about "Us and the virus: Understanding the COVID-19 pandemic through a social psychological lens," bringing the psychological theory of need satisfaction to bear on the social consequences (both the stressors and protective factors) of the pandemic at the individual, immediate social network, institutional and wider societal levels. Studies they reviewed reveal a complex picture in relation to loneliness (much discussed across society due to the social/physical distancing virus containment measures) and pandemic-related reorganization to social networks. Role conflicts emerged for families, especially with women and men balancing gender roles of caring and working. A sense of shared social identity ("we") broadly emerged as a stress buffer. Compliance with measures against the virus, which were the only defense before the vaccinations took on the heavy lifting, is found to be heavily dependent on various forms of trust (in institutions and in other people also to comply). Finally, the authors consider conspiracy theories the "infodemic," with a clear connection between conspiracy beliefs and compliance behaviors. This review is one of only two currently on this actual topic, it is theory-driven and places loneliness in the context of social networks, social role conflicts, and social identity.

Buecker and Horstmann (2021) offer "Loneliness and social isolation during the COVID-19 pandemic: A systematic review enriched with empirical evidence from a largescale diary study." This paper considers in depth this social topic which has important implications for social society and social stability as well as for health. The systematic review offers some interesting findings from the studies that did take measurements before the pandemic so were longitudinal in design. While differences in ways of measuring produced rather a mixed bag of results, most found loneliness had increased in the pandemic. The paper is one of few reviews in this area. The authors' empirical study is a diary study that reported daily assessments of the quality and quantity of social relationships. The size and ecological validity of the study allow it to make an important contribution. It showed people reporting the quality of social interactions as, on average lower and also reporting fewer social contacts than pre-pandemic, although over time, this lessened. This paper offers a useful lesson in the careful planning that is required properly to assess a phenomenon such as loneliness in a pandemic.

Esposito and colleagues (2021) have provided "Wellbeing and the COVID-19 pandemic: A community psychology systematic review," using PRISMA methodology that draws on community psychology and the core elements of a sense of community, participation, and empowerment to explore the effects of the pandemic. Using this frame directly leads the authors to consider a public benefit. The key messages emerging from their review include the protective nature of trust in institutions, the need to foster community connectedness, fostering online communication, and the importance of factors such as sense of community to well-being. The authors recommend drawing on their findings for effective community-based strategies to improve well-being in a pandemic.

Politi and coauthors (2021) in "The impact of COVID-19 on the majority population, ethno-racial minorities, and immigrants: A systematic review on threat appraisals from an inter-group perspective," a systematic literature review, address the unequal impact of COVID-19. The authors consider threat using a broad and integrated definition in the wider context of the disaster literature and the different experiences of the majority, ethnic minority, and immigrant 
populations. They derive four threats applicable to all: life, psychological needs, livelihood and financial, social and political; and four applicable to minorities: stigma and discrimination, stress sensitization, legal vulnerability, marginalization. They identify the need for research to give sufficient attention to minorities and the longer term and social level threats rather than privilege the majority and individual level. They briefly also consider the consequent psychological processes that drive either conflict or prosociality. This paper is welcome as it broadens consideration of the pandemic threat to the social-psychological level, looking at Intra- and inter-group outcomes (cooperation and conflict) and focusing on minorities.

\section{Mental Well-Being for the Individual}

The paper by Wirkner and colleagues (2021) "Mental health in times of the COVID-19 pandemic: Current knowledge and implications from a European perspective" reviews longitudinal studies on the impact of the COVID19 pandemic on the mental health of European populations, so there is comparison over time. They postulate that COVID-19 causes stress on multiple dimensions given the long time for which the virus has been a threat. The studies reviewed considered the overall impact on mental health, age-specific risk factors, social factors, and existing physical or mental health conditions. Young age or transitional life stage; living alone and perceived loneliness; female gender, having a young family; pre-existing health conditions do emerge as risk factors, in other aspects the findings are more nuanced. An unexpected finding might be the inconsistent results from studies making comparisons with pre-pandemic levels of mental distress, with some even reporting lower levels during the pandemic. They found some protective factors, including resilience and social contact. Overall, the authors make the point that the interplay of risk and protective factors and the impact of protective measures against the virus is not yet fully understood, and chronicity may be yet to emerge. This paper adds, among other things, in terms of its approach by considering the social as well as the individual dimension, in its consideration of the protective factors, and by identifying the conflicting messages from some of the longitudinal research, which then sets the agenda for further work in the field seeking explanations for apparent discrepancies.

Erbiçer and colleagues (2021) take a condition-specific approach and address mental health with their paper "The relationship between fear of COVID-19 and depression, anxiety, and stress: A meta-analysis." The purpose of their study was to consider the relationship between fear of COVID-19 and depression, anxiety, and stress. They found a strong relationship between the fear of COVID19 and anxiety, which was also related to age; there were moderate effect sizes in the relationships between the fear of COVID-19 and depression and stress. This paper is important in that it looks at a specific stressor, that is, fear of COVID-19. Methodologically it is valuable as it is the first meta-analysis, not just a review, in this area. It extends our understanding of individual differences (gender, age, etc.) in mental health by considering how they relate to COVID-19 fear.

\section{Individual Difference and Behavior}

Two papers then follow on the topic of personality traits (patterns of thinking, feeling, and behaving that generally persist and are stable over time) and COVID-19 that are complementary, and we encourage the reader to consider them together.

Bacon and colleagues (2021) make a broad assessment of the role of personality in relation to COVID-19 feelings and behaviors in "Emotional and behavioral responses to COVID-19: Explanations from three key models of personality." They find that personality does have a role. For example, neuroticism is associated with emotional difficulties and maladaptive coping, extraversion with poor adherence to social distancing, conscientiousness with compliance with virus containment measures. On the other hand, conscientiousness, because of preplanning and resilience, is associated with negative behaviors such as panic buying, whereas honesty-humility is not. People also experience a sense of conflict between a desire to be safe from the virus and a desire for normality. This paper is a welcome overview showing that personality has a part to play in different outcomes in relation to COVID-19 and demonstrating that strategies to fight against the virus should be modulated for different personality types.

Ścigała and colleagues (2021) have tackled the challenging issue of so-called "dark" personality traits in "Aversive personality and COVID-19: A first review and meta-analysis." This matters because a disposition to behave in a way that is not prosocial and considerate of others can adversely affect the containment of the virus. The authors reviewed and analyzed a substantial body of studies on aversive personality traits and also those showing low honesty-humility. They have demonstrated that people with higher scores in aversive personality traits were less likely to consider the measures against the virus were valuable, less likely to comply with them, and less likely to adopt prosocial behaviors towards other people in relation to COVID-19. This paper is a meta-analysis, lending strength to the finding that considering aversive personality traits is important when developing virus containment measures.

Korn and colleagues (2021) studied "Age differences in COVID-19 preventive behavior: A psychological perspective," motivated by the need for preventive behaviors 
across the age span to contain the virus, not just from the more-compliant-because-more-vulnerable older population. This large theory-driven study looked at whether policies have an impact on the age differences in terms of compliance behaviors (wearing of face coverings and avoiding social gatherings), and further whether policies also impact the relationship between perceptions of risk and levels of trust in how people behave. The comprehensive introduction in this paper has an interesting analysis about age differences and risk varying dependent on how risk is conceptualized and operationalized. All in all, mandatory policies did reduce differences in behaviors related to age and risk perception, and where trust in institutions is higher, so is compliance.

The work by Brailovskaia and team (2021) "Social media as information source, stress symptoms and burden caused by Coronavirus (COVID-19): A cross-national investigation of predictors" is a large cross-sectional multi-country study of seven European countries plus the USA on social media use as a source of COVID-19 information, and the psychological burden experienced by users. The study revealed that almost half of participants were regular social media users and that depending on how social media is used by people to get their information about COVID-19, use can foster stress symptoms and increase the emotional and behavioral burden during the pandemic. The requirement for social/physical distancing to contain the pandemic increased social media use, and so it is a particularly salient topic in this context. This is especially so in relation to participatory rather than static social media, as content can quickly go beyond static consumption of official material. The authors note their results suggest, while the methodology does not allow causality to be demonstrated, it is important to call public attention to how they use social media, as citizens may not be aware of the potential negative impact of social media use in an uncertain crisis such as the pandemic.

\section{Generating, Using, and Disseminating Evidence}

The EFPA News and Views has returned for this issue to provide a contribution related to the work of EFPA on COVID-19. In it, Karayianni, with colleagues from EFPA Working Groups (2021) "Psychological science into practice during the COVID-19 pandemic: A European perspective" describes the role taken by EFPA in the pandemic in gathering together and sharing resources in the EFPA Psychologists' Support Hub. They consider evidence-based practice, the difficulties in a crisis situation when the evidence base is still developing and show the sort of thing that can be done with reference to three vignettes on e-mental health, older adults, and community-based interventions for social change in times of crisis.

\section{Contribution to the Knowledge Base}

Returning to the questions with which we started about the advancement of the psychological knowledge specifically in relation to COVID-19, one could say that a number of the questions posed in the call for paper have been addressed, at least in part, in considerable studies and systematic reviews.

As has been seen, we have systematic reviews and metaanalysis in our special issue, sometimes probably the only one to date, so there is a reliable reassessment of the knowledge base, not simply affirmation of existing thinking and selected research results. While new theories are not reported, there is most definitely an extension of existing theories in relation to COVID-19. We include some big studies, well-controlled for, which have taken an ethical stance, and which have real-world validity.

A number of questions have, however, been less well answered, including the influence of social and political circumstances and structures and the worlds of work and education. Also, special groups such as children, gender influences and special risk groups (e.g., those with physical or mental health conditions at risk of relapse) are perhaps not addressed sufficiently from the reader's point of view. The importance of possible interventions is also only briefly addressed, and there could be more preventive measures, perhaps. There are some methodological points, too, the reader might note. Not all the papers use a conceptual broad defined and structured method such as PRISMA, while this might have been desired, in practice, it did not fit how the papers evolved; while all have defined search criteria, not all engaged in or demonstrate an analysis of the reliability of their selected results. Other variables not considered in the text may, in fact, influence the results. Some may still be too tied to the knowledge base from previous disasters. Several authors caution about generalizing beyond the country/populations of their study. The social domain is considered from a community psychologist viewpoint, but it can be asked how well this can be differentiated from a social-psychology perspective, research in this domain is lacking the community level domain, which has been used in studies on other disasters.

Nonetheless, we hope there are some messages from this Special Issue collection to fulfill the need for translation of the science into the world of public policy, and that demonstrate what psychology can offer.

\section{Using the Main Messages}

We have discussed above the interface between the science and social and political policy world in relation to understanding COVID-19. Turning now to how the work in this Special Issue might be used in the world beyond science, we have considered what one "takeaway" from each paper 
readers of this special issue might want to use in their work. These messages continue to be important as the pandemic is still with us, and measures, including more recent vaccination uptake, continue to rely on human behavior. Here are our ideas, ordered as we have presented the papers; readers will find others of their own:

The social and community level

- Social connections and relationships (social networks, shared social identities, and trust in institutions and one another) are very important for social stability and need satisfaction. They can also generate problematic behaviors in a crisis context like a pandemic, such as by fostering conspiracies, thereby complicating crisis interventions.

- There is a need to prepare carefully designed studies (large scale, using methods that allow the inclusion of the whole population, and across time) to gain a fuller understanding of the quality and quantity of social relationships, and therefore loneliness, in a crisis situation, given the health and social consequences.

- Social and collective resources have an essential role and are fostered by authorities maintaining public trust and enabling connections and solidarity between people at the community level.

- The unequal impact of crises needs to be considered, and research should focus equally on minorities and the longer term and social level threats.

Mental well-being for the individual

- Risk groups for poor mental well-being (which will vary depending on the situation) should be identified early, and protective measures fostered.

- It is necessary to manage the fear level generated in the pandemic, so it is salient enough to drive appropriate protective behaviors and support continued functioning and not so much as to damage mental health.

Individual difference and behavior

- Health messages need to account for personality dimensions in fostering the desired behaviors, while not overly contributing to mental distress.

- Clear communication of behavioral expectations, regulations, and sanctions may help ensure people with aversive personality traits adhere to virus containment measures.

- Where public health measures are being complied with differently depending on age and varying perceptions of risk, putting in place stricter public health policies as well as building trust by communicating accurate information can have the desired behavioral impact.

- People need to be informed about how the way they use different types of social media to get information in a crisis can have different effects on their well-being.
Generating, using, and disseminating evidence

- There is a need to consider how new evidence is generated and how the existing evidence base can be used in a fast-moving crisis situation. This can be applied across different aspects of the discipline, including psychologically and socially oriented expertise.

As guest editors, we thank the senior editors of European Psychologist and publisher Hogrefe for the opportunity to edit this special issue, "Psychology, Global Threats, Social Challenge, and the COVID-19 Pandemic: European Perspectives." We are enormously grateful to the tireless reviewers and, of course, to the authors whose contributions we now commend to the reader.

\section{References}

Almeda, N., García-Alonso, C., \& Salvador-Carulla, L. (2021). Mental health planning at a very early stage of the COVID-19 crisis: A systematic review of online international strategies and recommendations. BMC Psychiatry, 21(1), Article 43. https://doi.org/10.1186/s12888-020-03015-y

Bacon, A. M., Krupic, D., Caki, N., \& Corr, P. J. (2021). Emotional and behavioral responses to COVID-19: Explanations from three key models of personality. European Psychologist, 26(4), 334-347. https://doi.org/10.1027/1016-9040/a000461

Bavel, J. J. V., Baicker, K., Boggio, P. S., Capraro, V., Cichocka, A., Cikara, M., Crockett, M. J., Crum, A. J., Douglas, K. M., Druckman, J. N., Drury, J., Dube, O., Ellemers, N., Finkel, E. J., Fowler, J. H., Gelfand, M., Han, S., Haslam, S. A., Jetten, J., ... Willer, R. (2020). Using social and behavioural science to support COVID19 pandemic response. Nature Human Behavior, 4(5), 460-471. https://doi.org/10.1038/s41562-020-0884-z

Brailovskaia, J., Margraf, J., \& Schneider, S. (2021). Social media as information source, stress symptoms and burden caused by Coronavirus (COVID-19): A cross-national investigation of predictors. European Psychologist, 26(4), 373-386. https://doi.org/ 10.1027/1016-9040/a000452

Buecker, S., \& Horstmann, K. T. (2021). Loneliness and social isolation during the COVID-19 pandemic: A systematic review enriched with empirical evidence from a large-scale diary study. European Psychologist, 26(4), 272-284. https://doi.org/ 10.1027/1016-9040/a000453

Carley, S., Horner, D., Body, R., \& Mackway-Jones, K. (2020). Evidence-based medicine and COVID-19: What to believe and when to change. Emergency Medical Journal, 37(9), 572-575. https://doi.org/10.1136/emermed-2020-210098

Council of the Sciences. (2021). Impulse aus der COVID-19-Krise für die Weiterentwicklung des Wissenschaftssystems in Deutschland. Positionspapier [Impulses from the COVID 19 crisis for the further development of the science system in Germany. Position paper]. Wissenschaftsrat. https://www. wissenschaftsrat.de/download/2021/8834-21.pdf?__blob= publicationFile\&v=1

Erbiçer, E. S., Metin, A., Çetinkaya, A., \& Sen, S. (2021). The relationship between fear of COVID-19 and depression, anxiety, and stress: A meta-analysis. European Psychologist, 26(4), 323-333. https://doi.org/10.1027/1016-9040/a000464

Esposito, C., Di Napoli, I., Marino, L., Agueli, B., Procentese, F., \& Arcidiacono, C. (2021). Well-being and the COVID-19 pandemic: 
A community psychology systematic review. European Psychologist, 26(4), 285-297. https://doi.org/10.1027/1016-9040/a000468

European Centre for Disease Prevention and Control. (2020). Coronavirus disease 2019 (COVID-19) in the EU/EEA and the UK - tenth update, 11 June 2020. ECDC.

European Commission. (2020a). European Commission's coronavirus response team. https://ec.europa.eu/info/live-worktravel-eu/coronavirus-response/overview-commissions-response/ european-commissions-coronavirus-response-team_en

European Commission. (2020b). Speech by President von der Leyen at the European Parliament Plenary on the European coordinated response to the COVID-19 outbreak. https://ec. europa.eu/commission/presscorner/detail/en/speech_20_532

European Council on Foreign Relations. (2020). European Solidarity Tracker.

Gruber, J., Prinstein, M. J., Clark, L. A., Rottenberg, J., Abramowitz, J. S., Albano, A. M., Aldao, A., Borelli, J. L., Chung, T., Davila, J., Forbes, E. E., Gee, D. G., Hall, G. C. N., Hallion, L. S., Hinshaw, S. P., Hofmann, S. G., Hollon, S. D., Joormann, J., Kazdin, A. E., ... Weinstock, L. M. (2021). Mental health and clinical psychological science in the time of COVID-19: Challenges, opportunities, and a call to action. American Psychologist, 76(3), 409-426. https://doi.org/10.1037/amp0000707

Holmes, E. A., O'Connor, R. C., Perry, V. H., Tracey, I., Wessely, S., Arseneault, L., Ballard, C., Christensen, H., Cohen Silver, R., Everal, I., Ford, T., John, A., Kabir, T., King, K., Madan, I., Michie, S., Przybylski, A. K., Shafran, R., Sweeney, A., ... Bullmore, E. (2020). Multidisciplinary research priorities for the COVID-19 pandemic: A call for action for mental health science. Lancet Psychiatry, 7(6), 547-560. https://doi.org/10.1016/S2215-0366 (20)30168-1

Karayianni, E., Van Daele, T., Lucanin, J. D., Lopižić, L., \& Carr, N. (2021). Psychological science into practice during the COVID-19 pandemic: A European perspective. European Psychologist, 26(4), 387-397. https://doi.org/10.1027/1016-9040/a000458

Kasherman, L., Madariaga, A., Liu, Q., Bonilkla, L., McMullen, M., Liu, S., Wang, L., Fazelzad, R., Karakasis, K., Heesters, A. M., \& Oza, A. M. (2021). Ethical frameworks in clinical research processes during COVID-19: A scoping review. BMJ Open, 11, Article e047076. https://doi.org/10.1136/bmjopen-2020-047076

Kniffin, K. M., Narayanan, J., Anseel, F., Antonakis, J., Ashford, S. P., Bakker, A. B., Bamberger, P., Bapuji, H., Bhave, D. P., Choi, V. K., Creary, S. J., Demerouti, E., Flynn, F. J., Gelfand, M. J., Greer, L. L., Johns, G., Kesebir, S., Klein, P. G., Lee, S. Y., ... Vugt, M. V. (2021). COVID-19 and the workplace: Implications, issues, and insights for future research and action. American Psychologist, 76(1), 63-77. https://doi.org/ 10.1037/amp0000716

Korn, L., Siegers, R., Eitze, S., Sprengholz, P., Taubert, F., Böhm, R., \& Betsch, C. (2021). Age differences in COVID-19 preventive behavior: A psychological perspective. European Psychologist, 26(4), 359-372. https://doi.org/10.1027/1016-9040/a000462

Politi, E., Lüders, A., Sankaran, S., Anderson, J., van Assche, J., Spiritus-Beerden, E., Roblain, A., Phalet, K., Derluyn, I., Verelst, A., \& Green, E. G. T. (2021). The impact of COVID-19 on the majority population, ethno-racial minorities, and immigrants: A systematic review on threat appraisals from an intergroup perspective. European Psychologist, 26(4), 298-309. https://doi.org/10.1027/1016-9040/a000460
Rijs, C., \& Fenter, F. (2021). The academic response to COVID-19. Frontiers in Public Health, 8, Article 621563. https://doi.org/ 10.3389/fpubh.2020.621563

Roehrle, B., \& Gale, N. K. (2020). Call for papers "Psychology, Global Threats, Social Challenge, and the COVID-19 Pandemic: European Perspectives" A Special Issue of European Psychologist. European Psychologist.

Rudert, S. C., Gleibs, I. H., Gollwitzer, M., Häfner, M., Hajek, K. V., Harth, N. S., Häusser, J. A., Imhoff, R., \& Schneider, D. (2021). Us and the virus: Understanding the COVID-19 pandemic through a social psychological lens. European Psychologist, 26(4), 259-271. https://doi.org/10.1027/1016-9040/a000457

Schenk, G. (2017). Historical disaster experiences. Towards a comparative and transcultural history of disasters across Asia and Europe. Springer.

Ścigała, K. A., Schild, C., Lilleholt, L., Moshagen, M., Zettler, I., \& Pfattheicher, S. (2021). Aversive personality and COVID-19: A first review and meta-analysis. European Psychologist, 26(4), 348-358. https://doi.org/10.1027/1016-9040/a000456

Sigahi, T., Kawasaki, B. C., Bolis, I., \& Morioka, S. N. (2021). A systematic review on the impacts of COVID-19 on work: Contributions and a path forward from the perspectives of ergonomics and psychodynamics of work. Human Factors and Ergonomics in Manufacturing. Advance online publication. https://doi.org/10.1002/hfm.20889

Tyhurst, J. S. (1951). Individual reactions to community disaster: The natural history of psychiatric phenomena. American Journal of Psychiatry, 107, 764-769.

Wirkner, J., Christiansen, H., Knaevelsrud, C., Lueken, U., Wurm, S., Schneider, S., \& Brakemeier, E.-L. (2021). Mental health in times of the COVID-19 pandemic: Current knowledge and implications from a European Perspective. European Psychologist, 26(4), 310322. https://doi.org/10.1027/1016-9040/a000465

Zeeb, H., Ahrens, W., Haug, U., Grabenhenrich, L., \& Pigeot, I. (2021). Epidemiologische Ansätze zur Klärung wichtiger Forschungsfragen zu COVID-19 - eine Übersicht [Epidemiological approaches to address key research questions on COVID19 - an overview]. Bundesgesundheitsblatt, Gesundheitsforschung, Gesundheitsschutz, 64(9), 1076-1083. https://doi. org/10.1007/s00103-021-03378-x

Published online January 5, 2022

\section{Nicola Gale}

European Federation of Psychologists' Associations

Grasmarkt 105 / 39

1000 Brussels

Belgium

nicola.gale@efpa.eu

\section{Bernd Roehrle}

Department of Psychology

University of Marburg

Gutenbergstr. 18

35032 Marburg

Germany

roehrle@staff.uni-marburg.de 


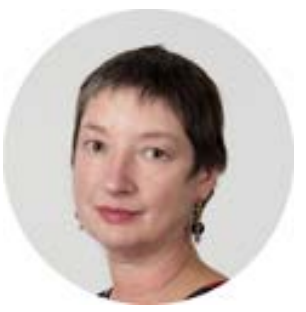

Nicola Gale (C.Psychol, FBPsS) is currently Vice President and Treasurer of the European Federation of Psychologists' Associations (EFPA) and led EFPA's response to COVID19. She is a former President of The British Psychological Society, is recently retired from City, University of London, and was a clinical lead in mental health and organizational development in the UK National Health Service.

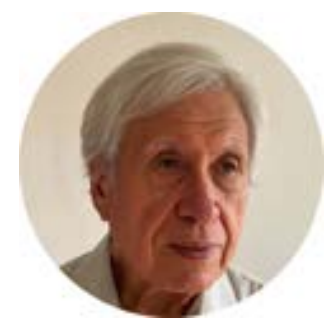

Bernd Roehrle (PhD) is a retired professor of clinical psychology and psychotherapy formerly of the University of Marburg, Germany. He is a member of the standing committee for community psychology (EFPA). He is the spokesperson of the German Network for Mental Health. His research focuses on the effectiveness of preventive interventions and mental health promotion. He also examines psychological approaches to social networks and contextual conditions of psychotherapy. 